$F G C x-28 E R 6063 \%$

DE-Á00270EV0203T

Radiopharmaceuticals for Diagnosis

\title{
PROGRESS REPORI
}

\section{For the Period 1 January 1988 through 31 December 1990}

\author{
David E. Kuhl, M.D. \\ Division of Nuclear Medicine \\ University of Michigan \\ Ann Aroor, MI $\mathbf{4 8 1 0 9}$
}

\section{Prepared tor the \\ Office of Healith and Emvironmental Research \\ Department of Energy \\ Washington, D.C.}

June 1990

\section{DISCLAIMER}

This report was prepared as an account of work sponsored by an agency of :' - United States This report was prepared as an account of work sponnor any agency thereof, nor any of their Government. Neither the United Stass or implied, or assumes any legal liability or responsi. bility for the accuracy, completeness, or usefulness of any information, apparatus, product, or bility for the accuracy, completeness, or usefulness of any infor process disclosed, or represents commercial product, process, or service by trade name, trademark, ence herein to any specific commen not necessarily constitute or imply its endorsement, recommanufacturer, or otherwise does not necessarily constitute or imply its endorsement, The views mendation, or favoring by the United States Government or any agency thereof. The views and opinions of authors expresserent 
'During this grant period 1 Jan 1988-31 Dec 1990, we have successtully developed a number of new approaches to fhorine-18 labeled compounds, prepared several new radiotracers for both animal studies and eventual clinical titals, and explored the utility of a high-quality incustrial robot in radiopharmaceutical applications. The progress during the last orant period is summarized briefly in the following sections. Publications arising from this research are listed below and can be found in Appendix 1 .

\section{Summary of eccomplishments.}

Project 1. New Methods of [ ${ }^{18}$ F]Fuorination.

(1) Production of [ $^{18}$ Ffluoride ion. When this grant period began, high specific activity [ $^{18}$ F]fluoride ion was not aveilable at this institution. We have constructed and fully tested a small volume (1 mi), high pressure water target for the routine production of [18F]ituoride ion using the ${ }^{18} \mathrm{O}(p, n)^{18} \mathrm{~F}$ nuclear reaction on enriched water. This target has proven exceptionally successful, and can be used to prepare large quantities of radionuclide $(700 \mathrm{mCl}$ ) is short times $(20 \mathrm{~min})$. This targei design is used in our routine production target, used daily for preparation of [ $^{18}$ Fjifuoride ion for both research in this grant as well as routine production of [ $^{18}$ FFDG and [ ${ }^{18}$ FGBR 12909 for clinical studies. To maximize rellabilty and allow for periodic cleaning (without concommitant downtime fer activation products to decay) we have actually constructed two identical targets which are rotated on a periodic basis. The target is more fully described in publication 17.

(2) New precursors for nucleophilic aromatic [ ${ }^{18}$ Ffluorination. We have prepared and fully examined a series of aryl trimethylammonium trfiluoromethanesulfonates as easy to prepare, stable, and highly reactive precursors for the symthesis of $\left[^{18} \mathrm{Flaryl}\right.$ thorides. The use of the cationic precursors allows both the use of lower reaction temperatures and the simple isolation of nuetral, [18 $\mathrm{F}$-labeled products (easily separated from charged precursor). We also examined aryl dimethylsultonium trifluoromethanesultionates as precursors, but these proved unsultable for high yield synthesis of aryl [ ${ }^{18} \mathrm{~F}$ fluorides.

This method of fluorination proved important in the developrnent of [ ${ }^{18}$ F]GBR 13119 and [ ${ }^{18}$ f]GBR 12909, new radiopharmaceuticals we have used in animal and human studies of the dopamine reuptake system. Furthermore, the symthesis and application of these cationic precurss has been adopled and duplicated by at least two other research groups worktwide.

This work is reported in publications 2 and 16.

(3) Synthesis of $\left[{ }^{18} \mathrm{~F}\right]$ fluorobenzyl bromide. We have examined the synthesis of 4-

[18 Ff] fluorobenzyl bromide as a precursor for radiopharmaceutical syntheses. The benzyl groups is an important functional group in a number of drugs, including dexetimide (muscarinic antagonist). We have examined three routes to fluorobenzyl bromide. Route (a) utilized the ritrile precursor, which was then reduced to the corresponding aldehyde and brominated. Route (b) again utilized the nitrile precursor, bit in this case the nitrile was reduced all the way to the hydrocarbon, which was then brominated. Finally, route (c) utilized the aldehyde as the precursor, which was in the second step brominated; this was the shortest route to the desired product. All of these synthestic routes have worked in low yield on both the carrier and carrier-tree \& ziles.

(4) Ring-opening reactions. The opening of cyclic ethers using dimethylboron bromide has been reported to yield the corresponding bromoalcohols, by the nucleophilic attack of bromide ion on the oxygen-Lewis acid complex. We have examined the possibitity of interception of the incipient activated ether by [ ${ }^{18}$ ffituoride ion, to yield the corresponing [ $\left.^{18} \mathrm{~F}\right]$ fluoroalcohol. Although the reagent was successtul in the ring-opening of cyctohexene oxide to the corresponding bromohydrin, in reactions where $1^{18}$ Fjituoride was added we could $m$ t detect the presence of the ${ }^{18} \mathrm{~F}$ ftuorohydrin. We are continuing our efforts in this novel approacn to thorination of alkanes.

5. $\left[{ }^{18}\right.$ F]Fluorination of thiophene rings. We have extended the nucleophilic aromatic substitution

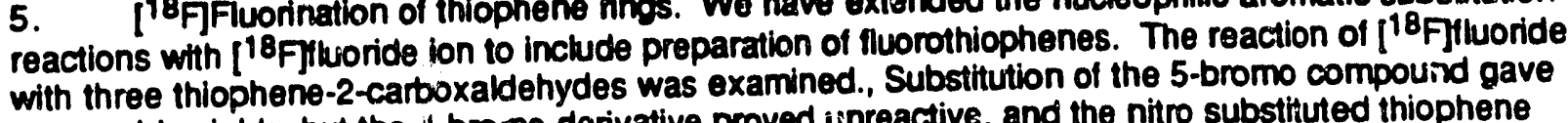
reasonable yields, but the 4-bromo derivative proved unreactive, and the nitro substituted thiophene 
gave small amounts of the $\left[{ }^{18}\right.$ fflluorothiophene but mostly decomposition products. These results are consistent with the literature on nucleophilic substitution in thiophene rings. This work is reported in paper 5.

6. Preparation of $\left[{ }^{18}\right.$ F]trffluoromethyl groups. A new and potentially powertul method for the synthesis of no-carrier-added [ ${ }^{18}$ F]tritluoromethyl groups has been devised, in collaboration with scientists from Parke-Davis $\mathrm{CO}_{\text {. }}$. Reaction of nca [ ${ }^{18} \mathrm{~F}$ fluoride ion with bromodifluoromethyl groups yields the ${ }^{18} \mathrm{~F}$ triftuoromethyl groups in good radiochemical yield. This reaction does not require high temperatures or Lewis acid catalysts. This is potentially a method for labeling a wide variety of pharmaceuticals which comtain trifluoromethyl substituents. This work is reported in paper 9.

7. Synthesis of [ ${ }^{18}$ F]thoro ethers. In an unusual reaction, we have examined the isotopic substitution of 1,1-difluoro-2,2-dichloroethyi ethers by [18 filluoride ion to yield the corresponding carrieradded, fuorine-18 labeled ethers. This reaction is an isotopic substitution; reaction in the ring was ruled out by successful synthesis of the benzene anabo, and the product obtained was identical by all chromatooraphic mothods with authentic starting material. This substitution by nucleophiles is precedented in the literature of pertluoroalkyt ethers. This work is reponted in papers 10 and 29

8. Now approach to fworocatechols. As part of our interests in the synthesis of fluorine-18 labeled catecholamines, such as dopamine, DOPA, and norepinephrine, we have examined a new symthetic route to no carrier added fluorocatechots. This approach utilizes a substituted o-salicaylaldehyde as the synthetic precusrsor, which is first substituted with [ ${ }^{18}$ Fjluoride ion and then oxidized to the catechol. By this route we have prepared NCA [ ${ }^{18}$ Ffluorocatechol. This work is reported in paper 28.

9. $\left.\quad{ }^{18} \mathrm{~F}\right]$ Fluorination of pyridazines. We have also examined the reaction of [ $\left.{ }^{18} \mathrm{~F}\right]$ fftuoride ion with chloropyridazine, nitrogen heterocycles which may be substitutes for benzene rings in certain drugs. We have successfully prepared several [18 fifluoropyridazines by this approach, including one which does not have activation by a electron-withdrawing group. This work is reported in publication 30 .

10. New radiotracer development. This research grant has supported in part the development of four spectfic types of radiotracers, dopamine reuptake inhibitors, calcium channel blockers, GABA reuptake inhibitors, and norepinephrine reuptake blockers.

a. Dopamine reuptake blockers. We have prepared, fully characterized, and extensively examined in aninmal models the new radioligands [ ${ }^{18} \mathrm{~F}$ GBR 13119 and [ ${ }^{18} \mathrm{~F}$ GBR 12909 . These are selective, high affinity liganos for the dopamine reuptake site. These radiotracers could be successfully utilized to image the DA uptake sites in animals, and [ ${ }^{18} \mathrm{FGBR} 12909$ was fuiher developed and brought into clinical trials. In attempts to improve the kinetic behaviour of this compound, a limited OSAR study was done, showing that some alterations (substitution of a thiophene ring) are allowed but other changes (shortening of alkyl chain) are not. The results in this area are in publications $1,2,3,4,5,7,8,12,13,15,19,20,22,23,25$, and 26 .

b. Norepinephrine reuptake blockers. We have prepared and examined in mice a specific high affinity ligand for the norepinephrine reuptake site, $I^{11} \mathrm{C}$ )nisoxetine. Although this radiotracer showed regional specificity and pharmacological specificity expected of a NE reuptake inhibitor, this compound shows high non-specific binding which may limit ths usefulness in vivo using PET. This data is reponted in publications 6,14 and 15 .

c. GABA reuptake inhibitors. In a collaboration with Parke-Davis company we have prepared several GABA reuptake compounds as potential mapping agemts for this site. These compounds utilized the cherrical synthesis methods developed for the GBA class of compounds. Animal work with these new compounds is underway. The chemical results are described in publications9,24 and 27.

d. Cakcium channel blockers. With an interest in the diakytpiperazine class of calcium channel blockers, due to thier similarity in structure to the dopamine reuptake inhibitors, we have prepared fluorine-18 labeled cinnarizine and flunarizine. Initial animals studies did not show regional binding to the DA uptake site. This work is reported in publications 11 and 21. 
Project 2. Applications of Robotics in Radiopharmaceutical Synthesis.

Our initial coals were to incorporate robotics into the synthesis of PET radiotracers. However, continued successtul chemical work (funded through DOE grant DE-FG02-87ER60561, D.E. Kuhl, P.I.) has eliminated the noed for a robot in most of our symtheses. We have therefore evaluated a robot in three other applications.

(1) Material handling. We have utilized the PUMA robot for the insertion and sealing of product vials into the "rabblits" used in our pneumatic delivery system. This was a high dose, manual operation which defeated the poals of recuction of radiation dose to personnel. The robot proved quite adept at this operation. This need was eliminated, however, by redesign of the rabbits and the pneumatic tube sonding station.

(2) Motabolite analysis. A routine, repetitive task in PET studies is the analysis of blood samples for radiotracer motabolites. This is an excellent applications point for robotics. To this end, we have modified standard laboratory equipment (syringes, contrifuges, vortex mixers) to opertate in tanderm with the PUMA rubot. The robot is thus capable of performing metabolite analyses using standand SEP-PAK technology for separations.

In this work we have showed the feasibility of a robotic approach to this task. It was clear that a simpler, less expensive robot (1.e., fewer degrees of freedom in the robot arm) would function just as well.

(3) Preparation of Copper-62 generators. Our most recent application of the robot is in the preparation of oenerators for copper-62. The chemistry behind the production of the parent nuctide, zinc62 , and assembly of a resin column used for the generator have been reproduced from the literature (our cyclotron, at $30 \mathrm{MeV}$, can prepare zinc-62 readity). We have assembled a compact robol cage (Figure 1) which fits inside a standard-sized chemical hood. The robot operates in the imverted position, as this provides the greatest envelupe of working space. Specialized hands for this robot have been constructed in our faclity. The robot system is currently undergoing evaluation as a safe, automated method for the production of copper-62 for PET studies in our institution.

Project 3. Review of fluorine-18 chemistry.

This grant has also supported the work by the Project Leader Michael R. Klboum in the research for and writing of a comprehensive review of fluorine-18 radiopharmaceutical chemistry, which is in press (10 be published by National Acadermy of Sciences). This is publication 31. 
Project 2. Applications of Robotics in Radiopharmaceutical Synthesis.

Our intial goals were to incorporate robotics into the synthesis of PET radiotracers. However, continued successtul chemical work (tunded through DOE grant DE-FG02-87ER60561, D.E. Kuhl, P.I. ) has eliminated the need for a robot in most of our syntheses. We have therefore evaluated a robot in three other applications.

(1) Material handling. We have utilized the PUMA robot for the insertion and sealing of product vials into the "rabbits" used in our pneumatic delivery system. This was a high dose, manual operation which defeated the goals of reduction of radiation dose to personnel. The robot proved quite adept at this operation. This need was eliminated, however, by redesign of the rabbits and the pneumatic tube sending station.

(2) Metabolite analysis. A routine, repettive task in PET studies is the analysis of blood samples for radiotracer metabolites. This is an excellent applications point for robotics. To this end, we have modified standard laboratory equipment (syringes, centrituges, vorte: mixers) to opertate in tandem with the PUMA robot. The robot is thus capable of pertorming metabolite analyses using standard SEP-PAK technology for separations.

In this work we have showed the feasibility of a robotic approach to this task. It was clear that a simpler, less expensive robot (i.e., fewer degrees of freedom in the robot arm) would function just as well.

(3) Preparation of Copper-62 generators. Our most recent application of the robot is in the preparation of generators for copper-62. The chemistry behind the production of the parent nuclide, zinc62 , and assembly of a resin column used for the generatur have been reproduced from the literature (our cyclotron, at $30 \mathrm{MeV}$, can prepare zinc-62 readily). We have assembled a compact robot cage (Figure 1) which fits inside a standard-sized chemical hood. The robot operates in the inverted position, as this provides the greatest envelope of working space. Specialized hands for this robot have been constructed in our facility. The robot system is currently undergoing evaluation as a safe, automated method for the production of copper-62 for PET studies in our institution.

Project 3. Review of fluorine-18 chemistry.

This grant has also supported the work by the Project Director Michael R. Kilboum in the research for and writing of a comprehensive review of fluorine-18 radiopharmaceutical chemistry, which is in press (to be published by National Academy of Sciences). This is publication 31. 


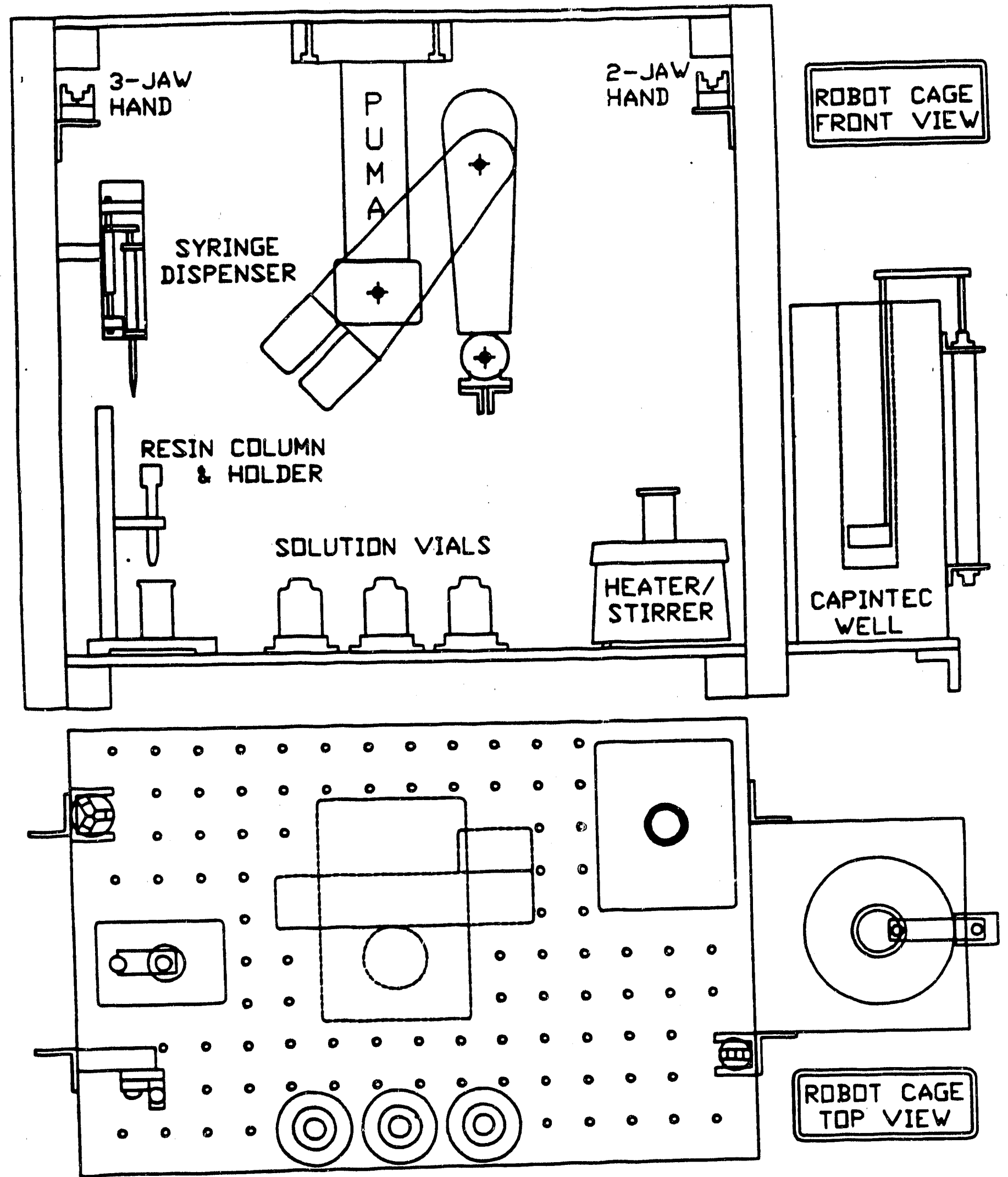

FIGURE 1 


\section{Publications 1 Jan 88 - 31 DeC 90}

\section{Manuscripts}

1. KIboum MR, Haka MS: Synthesis of [18 ] GBR 13119, a presynaptic dopamine uptake antagonist. Appl Radiat Isot 1988; 39:279-282.

2. Haka MS, Kiboum MR, Watkins GL: Aryl trimethylammonium trfluoromethane- sulfonates as precursors to aryl [18 Fffuorides: improved symthesis of [ ${ }^{18}$ F] GBR 13119. J Labelled Cmpd Radiopharm 1989; 27: 823-833.

3. KIboum MR, Haka MS, Mulholland GK, Sherman PS, Pisani T. Regional brain distribution of [18F]GBR 13119, a dopamine uptake inhibitor, in CD-1 and C57B1/6 mice. Eur J Pharm. 1989; 166:331-334.

4. Kilboum MR. Carey JE, Koeppe RA, Haka MS, Hutchins GD, Sherman PS, Kuhl DE: Blodistribution, dosimetry, motabolism and monkey PET studies of [18 F]GBR 13119. Imaging the dopamine uptake system in vivo. Nucl Med Biol 1989; 16:569-576.

5. Klboum MR. Thiophenes as phenyl bio-isosteres: Application in radiophamaceutical design I. Dopamine uptake antagonists. Nucl. Med. Biol. 1989; 16:681-686.

6. Haka MS, Kibourn MR. Synthesis and regional brain distribution of [ ${ }^{11}$ C]nisoxetine, a morepinephrine uptake inhibitor. Nucl Med Biol. 1989:16;771-774.

7. KIboum MR. In vivo binding of [ ${ }^{18}$ F GBR 13119 to the brain dopamine uptake system. Life Sciences 1988; 42:1347-1353.

8. Haka MS and Kiboum MR; Synthesis of [ ${ }^{18}$ f]GBR 12909, a dopamine reuptake inhibitor. J Labeled Compds Radiopharm, in press

9. Kiboum MR, Pavia MR, and Gregor VE; Synthesis of fworine-18 labelled GABA uptake inhibitors. Appl Radiat lsot, in press

10. Kilboum MR and Subramanian R. Synthesis of fluorine-18 labeled 1,1,-difluoro-2,2,-dichloroethyl aryl ethers by ${ }^{18} \mathrm{~F}$-for- ${ }^{19} \mathrm{~F}$ exchange. $J$ Labeled Compds Radiopharm

11. Kiboum MR: Synthesis of ${ }^{18} \mathrm{Fftunarizine.} \mathrm{Nucl.} \mathrm{Med.} \mathrm{Biol,} \mathrm{submitted}$

12. Kilboum MR, Mulholland GK, Sherman PS, and Pisani T: In vivo recovery of dopamine uptake sites after MPTP treatment of C57BL6 mice. Biogenic Amines, submitted

\section{Abstracts}

13. Kilboum MR, Haka MS, Ciliax GH, Kuhl DE: Synthesis and regional brain uptake of [F-18]GBR 13119, a dopamine uptake blocker. J Nucl Med 1988; $29: 767$.

14. Kilbourn MR, Jewett DM: Syntheses of carbon-11 labeled nisoxetine and fluoxetine, monoamine reuptake inhibitors. J Nucl Med 1988; $29: 932$.

15. Kilboum MR, Haka MS, Mulholland GK, Jewett DM, Kuhl DE: Synthesis of radiolabeled inhibitors of presynaptic monoamine uptake systems: [18 FGBR 13119 (DA), [ ${ }^{11}$ C]nisoxetine (NE) and [ ${ }^{11}$ Cfluoxetine (5-HT). J Labeled Cmpds radiopharm 1989; 26:412-414.

16. Haka MS, Kilboum MR, Watkins GL: Aryl trimethylammonium trifluoromethane-sulfonates as precursors to anyl 18 Ffiluorides. J Labeled Cmpds Radiopharm 1989; 26:17-19.

17. Mulholland GK, Hichwa RD, Kiboum MR, Moskwa J: A reliable pressurized water target for F-18 production as high beam currents. J Labelod Cmpds Radiopham 1989; 26:192-193.

18. Mulholland GK, Mangner TJ, Jowett DM, Kiboum MR: Polymer-supported nucleophilic radiolabeling reactions with $[18$ ffiluoride and $[11$ C Cjojanide ion or quatemary ammonium resins. I Labeled Cmpds Radiopharm 1989; 26:378-380.

19. Kilboum MR, Haka MS, Ciliax BJ, Penney JB, Young AB: In vivo autoradiography of 18 F]GBR 13119 binding in rat brain. Society for Neuroscience, 18th Annual Meeting, Toronto, 1988, Abstract 376.11.

20. Kilboum MR, Haka MS, Koeppe RA, Ciliax BJ, Penney JB, Kuhl DE: Development of [ $\left.{ }^{18} \mathrm{~F}\right] \mathrm{GBR}$ 13119 for PET studies of the dopamine reuptake system. J. Cerebral Blood Flow and Metabolism. 1989; 9:S15.

21. Kiboum MR: Symthesis of [F-18]tluorocinnarizine, a calcium channel blocker. J. Nuclear Medicine 1989; 30:753. 
22. Mulholland GK, Kllboum MR, Sherman PS, Pisani TL: In vivo changes in striatal binding of dopamine uptake inhibitor $1^{18}$ FGGB 13119 and muscarinic receptor ligand [11 C]-2a-tropanyl bendlate in MPTP lesioned C57BL/6 mice: dual tracer injection studies. Society for Neuroscience Annual Meeting, 1989, abstract 22.1.

23. Koeppe RA, KJboum MR, Frey KA, Penney JB, Haka MS, Kuhl DE: Imaging and kinetic modeling of [F-18]GBR 12909, a dopamine uptake inhibltor. Society of Nuclear Mediane 371 h Annual Moeting. Washington, D.C., June 1990.

24. Klboum MR, Pavia MS, Gregor V. Synthesis of thorine-18 labeled inhibitors of GABA reuptake. Society of Nuclear Medirine 37 h Annual Meeting, Washington, D.C., June 1990.

25. Haka MS, Klboum MR. Synthesis of [ ${ }^{18}$ F]GBR 12909 for human studies of dopamine reuptake stes. Society of Nuclear Medicine 37 h Annual Meeting. Washington, D.C.. June 1990.

26. Van Don ME, Chakraborty PK, Wieland DM, Klboum M. Dopamine uptake inhibitors: Comparison of 1251 and $18 \mathrm{~F}$-tabeled ligands. Society of Nuctear Medicine $37 \mathrm{ht}$ Annual Meeting, Washington, D.C., June 1990.

27. Kisboum MR, Pavia MS, and Gregor VE, Syntheses of fluorine-18 labeled inhibitors of GABA (0aminobutyric acid) reuptake. Eighth Interanational Sympordum on Radiophamacoutical chemistry, Princeton N.J., tune 1990

28. Chakraborty PK and KIboum MR, A new approach to the symthesis of no-carrier-added fluorine18 labeled fluorocatechols. Eighth interanational Symposium on Radiopharmaceutical chemistry, Princeton N.J., June 1990

29. KIboum MR and Subramanian R, Synthesis of fworine-18 labeled 1,1-diffuoro-2,2-dichloroethyl ary ethers by isotopic exchange. Eighth Interanational Symposium on Radiophamaceutical chemistry, Princeton N.J., June 1990

30. Mourad $A$ and Kllboum MR, [18F]Fluorination of heterocyclic rings: syntheses of [18F]fluoropyridazines by nucleophilic substitution. Elghth Interanational Symposium on Radiopharmaceutical chemistry, Princeton N.J., June 1990

Books

31. KIlboum MR. Fluorine-18 Labeling of Radiopharmaceuticals. National Academy Press, Washington, D.C., 1990, 149 Pp. National Technical Information Service, US Department of Energy, in press 
III. Postdoctoral scholars trained 1988-1990

Athough this DOE grant has not provided funds for the training of postdoctoral chemists, the grant has been used to support the laboratory work of a number of postdoctoral fellows. The following list of individuals were involved in this work during the grant period.

Dr. G. Leonard Watkins

Director of PET Chemisty

University of lowa

Dr. Michael S. Haka

Research Irvest gator

Division of Nuclear Medicine

University of Michigan

Amn Arbor, MI

Dr. Pulak Chakraborty

Research Fellow

Division of Nuclear Medicine

University of Michigan

Ann Arbor, MI

Dr. Alaa Mourad

Research Fellow

Division of Nuctear Medicine

University of Michigan

Ann Arbor, MI

Dr. Raghu Subramanian

Midwest Research Institute

Kansas City, MO

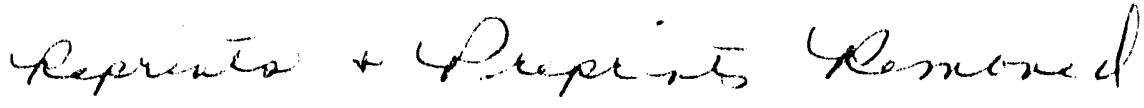



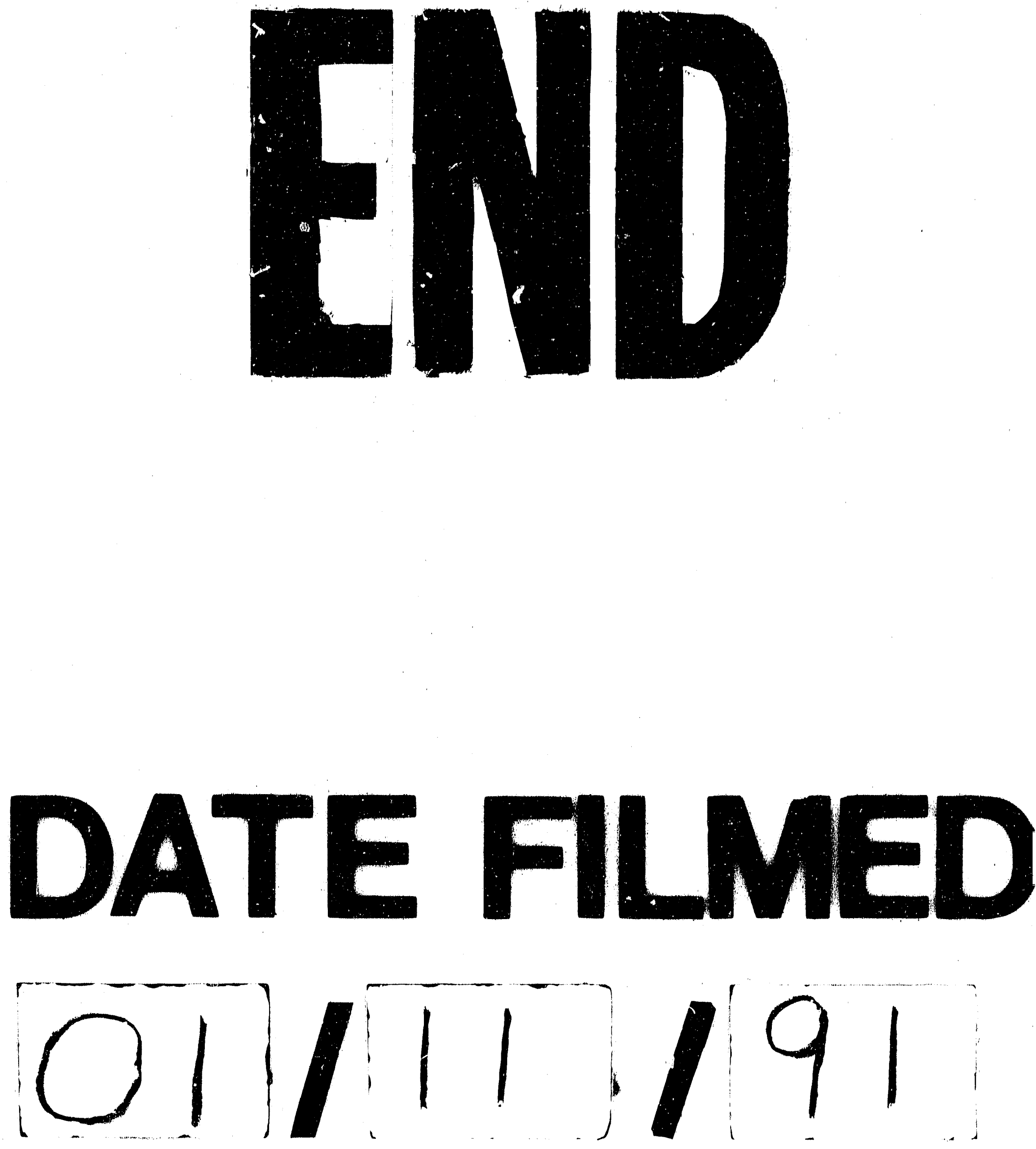
